\title{
AN OVERVIEW OF THE DIGITAL MILLENNIUM COPYRIGHT ACT OF 1998
}

\author{
Salvatore A. Marsico \\ Penn State University
}

\begin{abstract}
The Digital Millennium Copyright Act of 1998 (DMCA) supplements the Copyright Act of the United States. The DMCA is the enabling legislation required to implement two international treaties of 1996; namely, the World Intellectual Property Organization (WIPO) copyright Treaty and the World Intellectual Property Organization Performances and Phonograms Treaty. These treaties provide protection of copyrighted works on an international level. Participating countries must give equal protection to citizens of their country as well as to citizens of participating member countries. In addition, the DMCA addresses other copyright related issues. The objective of this article is to address the impact of the DMCA on educational institutions. The analysis focuses on the movement toward webcasting of material by institutions and their faculty. More specifically, as more faculty utilized the capability of the Internet a possibility arises that copyrighted material is broadcast without the copyright owner's permission. And the age-old question of whether an exception exists must be answered. Does fair use apply in light of DMCA? If so, to what extent and what hurdles must one overcome.
\end{abstract}

\section{Introduction}

The copyright act ${ }^{1}$ protects intellectual property that is "fixed in a tangible medium of expression ${ }^{2}$." The intellectual property that is of concern for faculty is that of copyright and the rights that flow from its ownership. The copyright protects original works of authorship such as notes, texts, and multimedia works amongst others. As with any property the owner has certain rights and these rights are often referred to as the "bundle of rights". The bundle of rights includes the rights to own it exclusively, exclude others from having or deriving any benefit from it, and alienating it; that is, to convey to others any rights which you may have in the property. However, many faculty projects are considered "work made for hire" 3 and as such are generally the property of the educational institution.

As technology has eroded the physical borders between countries the need has arisen to protect authors of intellectual property from foreign parties using it without permission. Foreign nations have also seen a need to protect ${ }^{4}$ their own authors from infringement by others, as such legislation was signed into law: The Digital Millennium Copyright Act of $1998^{5}$ (DMCA). The legislation is enabling in nature and implements two 1996 World Intellectual Property Organization (WIPO) Treaties, one of which is the WIPO Copyright Treaty. This treaty makes technical amendments to U.S. copyright law; that is, to protect works subject to previous treaties which fell into the public domain because of a failure to comply with formalities that then 
existed in U.S. law. In addition, the DMCA creates prohibitions for circumvention of technological measures used by the copyright owners to protect their works and one on tampering with copyright management information ${ }^{6}$. This paper will focus on the impact of the DMCA on faculty and nonprofit educational institutions involved in the both traditional classroom activities and some form of distance education.

\section{DMCA and the Copyright Act}

The DMCA as signed into law by President Clinton implements treaties ${ }^{7}$ binding the United States and member countries to protect the intellectual property of the respective owners of such property. This enabling legislation makes changes to the existing United States Code on copyright by modifying Section 104 of the Copyright Act establishing conditions of eligibility for protection under U.S. law for works from other countries. The DMCA is divided into five titles $^{8}$, four of which are of particular importance to faculty and their duties as educators, researchers, and advisors to graduate students.

Title I creates legal protection against the "circumvention of effective technical measures that are used by copyright owners to protect their works and one on tampering with copyright management information, 9, where circumvention refers to a person or entity developing hardware and software to overcome any barriers to copying that the rightful owner of the copyright may have put into place. This constitutes developing a device to "descramble a scrambled work, to decrypt an encrypted work, or otherwise to avoid, bypass, remove, deactivate, or impair a technological measure, without the authority of the copyright owner. ${ }^{10 "}$ However, special attention by the framers of the DMCA prevented a disaster for educational institutions by incorporating language that provided for the use of copyrighted works without fear of infringement ${ }^{11}$. Thus the importance of Title I lies in the fact that "fair use" of copyrighted work is still protected. Fair use is a defense that is raised in a lawsuit of copyright infringement when the unauthorized use is made for purposes of teaching, research and scholarship. To qualify for this defense four statutory criteria must be evaluated because there is no brite line legal test giving a clear and definitive yes or no answer. The four factors in determining whether the use made of a work in any particular case is a fair use the factors to be considered shall include-

"(1) the purpose and character of the use, including whether such use is of a commercial nature or is for nonprofit educational purposes;

(2) the nature of the copyrighted work;

(3) the amount and substantiality of the portion used in relation to the copyrighted work as a whole; and

(4) the effect of the use upon the potential market for or value of the copyrighted work."12

The balancing of the factors leads to, at times, unwanted results. However, for educators, and researchers it is quite easy to stay within the scope of the copyright law given that there are a number of provisions granting educators and researchers fair use of material. In fact, notwithstanding the provisions of section 106 which grants exclusive rights to the copyright owner, "display" of work by an instructor in the course of face to face teaching is not infringement as long as the education institution is nonprofit ${ }^{13}$. To "display" a work means to show a copy of it, either directly or by means of a film, slide, television image, or any other device or process or, in the case of a motion picture or other audiovisual work, to show individual images nonsequentially ${ }^{14}$.

Proceedings of the 2001 American Society for Engineering Education Annual Conference \& Exposition Copyright (C) 2001, American Society for Engineering Education 
Of concern to universities is Title II of the DMCA that adds a new section $512^{15}$ to the Copyright Act that creates four new limitations ${ }^{16}$ on liability for copyright infringement by online service providers (OSP). The limitations are for (1) transitory communications, (2) system caching, (3) information residing on system or networks at the directions of users, and (4) information location tools. Transitory communications occur when the service provider acts as conduit transmitting digital information at someone else's request. System caching enables the service provider, in this case the educational institution, to reduce its bandwidth requirements by retaining a copy of material so that subsequent requests for the same material is fulfilled by the transmission of the retained copy rather than retrieving the original source. For information residing on networks, the infringing material is on a website and hosted by the system of the institution and applies to storage of the information at the direction of the user. And the limitation for information location tools refers to hyperlinks, online directories, and search engines with respect to referring users to a site that contains infringing material. Furthermore, the service providers must meet conditions to qualify for any limitation. The service provider must: "(1) adopt and reasonably implement a policy of terminating ..... subscribers who are repeat infringers, and (2) accommodate and not interfere with technical measures." ${ }^{17}$ These technical measures are those used by copyright owners to identify and protect copyrighted works.

An educational institution seeking safe harbor in these provisions ${ }^{18}$ must look to the new section 512 of the Copyright Act governing the application of these limitations to nonprofit educational institutions to qualify as a "service provider." 19 As with any educational institution, faculty, students, and administration are provided access to the network and the institution maintains the network permitting digital online communications of material of the user's choosing, without modification to the content of the material as sent or received. Taking the broad definition of service provider as set out in the Copyright Act, "a provider of online services or network access, or the operator of facilities thereof," indeed meet this definition. If in fact the nonprofit educational institution qualifies for the safe harbor provision then the faculty member or graduate student employee who is performing a teaching or research function shall be considered "a person other than the provider" for the purposes of attributing the infringing activity to. ${ }^{21}$

While the online copyright infringement liability limitation set by the DMCA provides for a complete bar on money damages and limits the availability of injuctive relief ${ }^{22}$, the failure of the online service provider to qualify for one of the limitations does not by itself necessarily make it liable for copyright infringement. As with any copyright infringement case the owner of the copyright needs to make the case that the service provider infringed the copyright. In fact, the service provider has all the available defenses that an individual would have available including "fair use." 23 In addition, this title of the DMCA establishes a procedure for the copyright owner to obtain a subpoena from federal court identify the person alleged to be infringing. ${ }^{24}$

Title IV of the DMCA is especially important for institutions that either have a distance education mission or are increasing student enrollments through distance education programs. In fact, educators are further protected for transmissions of fair use works to off campus locations as part of a distance education program through the use or expansion of the exception for instructional broadcasting. ${ }^{25}$ However, problems may arise from the fact that otherwise protected "fair use" classroom may become infringing material when used for later broadcasting. That is, face to face lectures using copyrighted material allowed under the "fair use" doctrine become 
productions, i.e. streaming video or compressed video, and thus may not be protected. This raises a potential problem for faculty and the institution when releases are not obtained from all parties involved: the owner of the copyrighted material, instructor, and students. Generally, lecture materials are the intellectual material of the preparer so long as the notes are not considered "work for hire." Therefore, faculty may argue that the lecture notes are not a requirement to lecture and such are the rightful owners of the copyright, whereas the educational institution may claim a copyright in the televised product. However, the faculty may still have a claim of copyright on the their contribution to the televised or taped product since the Copyright Act grants the owner of a copyright the exclusive right to create derivative works. ${ }^{26}$ A derivative work is:

"a work based upon one or more preexisting works, such as a translation, ....., or any other form in which a work may be recast, .... or adapted. A work consisting of editorial revisions, ....., or other modifications, which, as a whole, represent an original work of authorship, is a "derivative work"

Students may also have a claim for copyright protection for their contribution to the lecture that is being broadcast live or taped for later viewing. One may recall that a copyright interest arisen when the original work of authorship is fixed in a tangible medium of expression of which a recording is certainly a tangible medium. ${ }^{27}$

Like many designers and engineers new and innovative designs can be protected under the Copyright Act as an original design of a useful article that makes the article attractive and distinctive in appearance. ${ }^{28}$ In particular, chapter 13 of the Copyright Act incorporates Title V of the DMCA: Vessel Hull Design Protection Act which protects not only any useful article as described in section 1301 but also specifically enumerates vessel hull designs and molds and plugs used to make an exact duplication. Whereas works of authorship created after 1978 have a copyright protection period of the life of the author plus 70 years, and whereas the "work for hire" protection remains for 95 years from first publication or 120 years from the time of creation, useful articles qualifying under chapter 13 are granted protection for a 10 year period. ${ }^{29}$

\section{Recommendations}

As with any issues involving a number of participants the potential for disagreements and discord increases exponentially with the number of participants. In this particular instance the possible participants that may claim a copyright interest, in face to face lectures, or digitally transmitted, or telecourses, are faculty, students and the educational institution. In addition, the original copyright owner of "fair use" material may have a copyright interest as a derivative work. Thus, while Section 110(2) specifically exempts the performance and display of certain materials transmitted for instructional purposes, no protection exists for later distribution of the program or lecture. Therefore, the nonprofit educational institution should minimize the number of transmissions of lectures or telecourses without obtaining licensing or waivers from the copyright owners since the safe harbor provision will not offer any protection. In addition, faculty should refrain from using active student participation when preparing a lecture for digital transmission, and faculty should eliminate any use of "fair use" material from these digitally broadcast lectures.

\section{Conclusion}

Proceedings of the 2001 American Society for Engineering Education Annual Conference \& Exposition Copyright (C) 2001, American Society for Engineering Education 
In summary, nonprofit educational institutions have a heavy burden to carry and are required to adhere to the letter of the law just like any other person. Where the institution produces, distributes, and videotapes programming, the fair use defense and safe harbor provisions will not completely insulate the institution. Therefore, these institutions should obtain written clearances permitting the use of materials for educational programming. Accordingly, the nonprofit educational institution should require faculty and other contributors to relinquish copyright ownership rights to any materials used for the delivery of the lecture. And, the clearances should cover initial transmission, copying, and future uses of the material(s).

17 USC $\$ 101$, et seq.

${ }^{2} 17$ USC $\$ 101$

${ }^{3} 17$ USC Id.

${ }^{4} 17$ USC $\$ 104$ A "work made for hire" is - (1) a work prepared by an employee within the scope of his or her employment; or (2) a work specially ordered or commissioned for use as a contribution to a collective work, or as a part of a motion picture or other audiovisual work, as a translation, as a supplemtary work, as a compilation, as an instructional text, as a test, as answer material for a test, or as an atlas, if the parties expressly agree in a written instrument signed by them that the work shall be considered a work made for hire.

${ }^{5}$ DMCA referred to as: Pub. L. No. 105-304, 112 Stat. 2860 (Oct. 28, 1998)

${ }^{6}$ DMCA: Title I, "WIPO Copyright and Performances and Phonograms Treaties Implementation Act of 1998 "

${ }^{7}$ the WIPO Copyright Treaty and the WIPO Performances and Phonograms Treaty

${ }^{8}$ Title I: see note 7

Title II: the "Online Copyright Infringement Liability Limitation Act"

Title III: the "Computer Maintenance Competition Assurance Act"

Title IV: Miscllaneous Provisions

Title V: the "Vessel Hull Design Protection Act"

${ }^{9} 17$ USC $\$ 1201(a)$

${ }_{11}^{10} 17$ USC $\$ 1201(\mathrm{a})(3)$

11 USC $\$ 1201(\mathrm{a})(1)(\mathrm{B})$

${ }^{12} 17$ USC $\$ 107$

${ }^{13} 17$ USC $\$ 110$ Limitations on exclusive rights: Exemption of certain performances and displays.

${ }^{14} 17$ USC $\$ 101$

${ }^{15} 17$ USC $\$ 512$

1617 USC $\$ 512(\mathrm{a})-(\mathrm{d})$

${ }^{17} 17$ USC \$512(i)

${ }^{18}$ DMCA Title II: Online Copyright Infringement Liability Limitation

${ }^{19} 17$ USC 512(k)(1)(A)

${ }^{20} 17$ USC $\$ 512(\mathrm{k})(1)(\mathrm{B})$

${ }^{21} 17$ USC $\$ 512(\mathrm{e})$

${ }^{22} 17$ USC $\$ 512(\mathrm{j})$

${ }^{23} 17$ USC \$512(1)

${ }^{24} 17$ USC $\$ 512(\mathrm{~h})$

${ }^{25} 17$ USC $\$ 110(2)(\mathrm{c})(\mathrm{i})$

${ }^{26} 17$ USC $\$ 106$

${ }^{27} 17$ USC $\$ 101$

${ }^{28} 17$ USC \$1301, et seq

${ }^{29} 17$ USC $\$ 301$, et seq

SALVATORE A. MARSICO

Proceedings of the 2001 American Society for Engineering Education Annual Conference \& Exposition Copyright (C) 2001, American Society for Engineering Education 
Salvatore A. Marsico is an Assistant Professor of Mechanical Engineering and Legal Issues in Engineering. He received Bachelor of Engineering and Master of Engineering degree from Manhattan College in New York, and a Juris Doctor from the Beasley School of Law, Temple University, Philadelphia, Pennsylvania. 